\title{
Recognizing menopause in women with amenorrhea induced by cytotoxic chemotherapy for endocrine-responsive early breast cancer
}

\author{
Francesco Torino, Agnese Barnabei ${ }^{1}$, Liana De Vecchis ${ }^{2}$, \\ Marialuisa Appetecchia ${ }^{1}$, Lidia Strigari ${ }^{3}$ and Salvatore M 'Corsello ${ }^{4}$
}

Department of Internal Medicine, Chair of Medical Oncology, University of Rome "Tor Vergata", Rome, Italy ${ }^{1}$ Endocrinology Unit, National Institute of Cancer "Regina Elena", Rome, Italy

2Department of Neuroscience, Chair of Medical Oncology, University of Rome "Tor Vergata", Rome, Italy

${ }^{3}$ Laboratory of Medical Physics and Expert Systems, National Institute of Cancer "Regina Elena", Rome, Italy

${ }^{4}$ Endocrinology Unit, Università Cattolica, Sacro Cuore, Rome, Italy

(Correspondence should be addressed to S M Corsello, Università Cattolica, Via Federico Cesi 72, I-00193 Rome, Italy; Email: corsello.sm@mclink.it)

\begin{abstract}
Cytotoxic anticancer treatment may induce amenorrhea or menopause to a variable extent. These side effects may not only impair or impede fertility but also cause sexual dysfunction, bone loss, and menopausal symptoms, with a strikingly negative effect on quality of life in many women. Aromatase inhibitors (Als) are a recommended adjuvant endocrine treatment option in postmenopausal patients affected by early breast cancer (EBC) but are contraindicated in premenopausal women and in those with residual ovarian function. Women over 40 years of age with chemotherapy-induced amenorrhea $(\mathrm{ClA})$ and routine hormonal levels consistent with menopause may receive an $\mathrm{Al}$ as adjuvant endocrine treatment. For these women, the tools available to identify menopause do not appear to be completely reliable. This review focused on the pathophysiology of ovarian toxicity induced by cytotoxic agents and on potentially useful methods to diagnose chemotherapy-induced menopause in patients treated with adjuvant chemotherapy for endocrine-responsive EBC. Moreover, practical approaches are proposed to distinguish true menopausal women, who would benefit from Als, from those with transient or persistent CIA.
\end{abstract}

Endocrine-Related Cancer (2012) 19 R21-R33

\section{Introduction}

Breast cancer is the most common invasive malignancy in women of reproductive age (Jemal et al. 2010). At diagnosis, $\sim 30 \%$ of patients are premenopausal and 10\% are 35-45 years old (Bines et al. 1996). Adjuvant endocrine therapy (ET) improves survival in patients with endocrine-responsive EBC (EREBC; Goldhirsh et al. 2011). For patients who are premenopausal, tamoxifen, and/or ovarian function suppression (OFS) is considered as standard option. For postmenopausal women, aromatase inhibitors (AIs) are recommended as up-front treatment or sequentially after tamoxifen because these reduce the risk of recurrence in EREBC (Burstein et al. 2010). These drugs, however, are contraindicated in premenopausal women and in those presenting residual ovarian function (Burstein et al. 2010).

Adjuvant chemotherapy (CT) prolongs survival in women with $\mathrm{EBC}$, even in the case of endocrineresponsive disease, particularly if patients are $<50$ years of age (EBCTCG 2005). Therefore, premenopausal patients with EREBC may sequentially receive adjuvant CT and ET (Goldhirsh et al. 2011, NCCN Breast Cancer Guidelines 2011).

As a consequence of CT, a percentage of women, who are pre/perimenopausal at the time of diagnosis, develop transient amenorrhea (chemotherapy-induced amenorrhea (CIA)) or menopause (chemotherapyinduced menopause (CIM)). While these side effects predict better clinical outcomes (Walshe et al. 2006, 
Swain et al. 2010), they raise a number of concerns regarding residual fertility, sexual dysfunction, bone loss, and menopausal symptoms, with a marked, negative impact on quality of life (Schover 2008).

Also, the choice of the most suitable adjuvant ET for women affected by EREBC and CIA may be challenging, and a correct diagnosis of menopause is crucial. In clinical practice, physicians may ascertain whether a woman with CIA is menopausal by only using a nonvalidated pool of clinical data, including age, menstrual history, vasomotory symptoms (Box 1), and the likelihood of gonadal toxicity from CT
(Table 1), together with hormonal evaluations. However, information obtained from the assessment of these parameters may be misleading. In a recent survey, 45 patients with a median age of 47 years (range: 39-52), affected by EREBC with CIA and hormonal levels consistent with menopause, received AI therapy. At a median of 12 months (range: 4-59), 27\% of these women regained ovarian function and one became pregnant. Median age at restart of ovarian function was 44 years (range: 40-50; Smith et al. 2006).

In this report, the pathophysiology of primary ovarian insufficiency (POI) induced by $\mathrm{CT}$ and the

\section{Box 1 Definitions of primary ovarian insufficiency, amenorrhea, and menopause}

In primary ovarian insufficiency (POI), the cause of ovarian dysfunction is inherent in the ovary. In most cases, an unknown mechanism leads to premature exhaustion of the resting pool of primordial follicles, but POI might also result from genetic defects, autoimmunity, surgery, radiotherapy, or cytotoxic chemotherapy (CT). POI is defined as amenorrhea for at least 3 months, and two recordings of serum concentrations of $\mathrm{FSH}>40 \mathrm{IU} / \mathrm{l}$ and low estradiol $\left(\mathrm{E}_{2}\right)$ levels $(<10 \mathrm{pg} / \mathrm{ml})$ at least 1 month apart in a woman aged $<40$ years (De Vos et al. 2010). The disorder usually leads to sterility.

The term amenorrhea indicates the absence of menstrual cycles on a permanent, intermittent, or temporary basis and may be classified as primary or secondary. In primary amenorrhea, menstrual periods never appear (by age 16), karyotype being abnormal in about $50 \%$ of cases. Secondary amenorrhea, with the exception of hysterectomy and uterine disorders, is defined as the lack of menses for more than three cycles or for 6 months in women who previously had menses. It may be due to pregnancy or caused by infections, uncontrolled diabetes mellitus, malnutrition, hypothalamic or thyroid dysfunction, hyperprolactinemia, and polycystic ovary syndrome. Secondary amenorrhea together with increased levels of FSH often indicates ovarian insufficiency. However, there are no established gonadotropin cutoff values suggesting the onset of ovarian insufficiency, probably because the decline in ovarian function is intermittent and sometimes erratic (De Vos et al. 2010).

Menopause defines the permanent cessation of menses resulting from the loss of ovarian follicle activity and marks the end of the natural reproductive life. Menopause is the physiological end stage of ovarian aging, which corresponds to a continuous process of insufficiency. Natural menopause can only be retrospectively established after 12 consecutive months of spontaneous amenorrhea. The age of natural menopause shows a normal distribution with a mean at $\sim 51$ years, range 40-60 years (De Vos et al. 2010). In postmenopause, FSH levels are markedly increased, $E_{2}$ levels are low, whereas inhibin-B and anti-Müllerian hormone (AMH) are very low or undetectable (Knauff et al. 2009).

A variety of definitions of menopause have been used in breast cancer clinical trials (Clemons \& Simmons 2007). According to the National Cancer Comprehensive Network, criteria for determining menopause may alternatively include bilateral oophorectomy, age $\geq 60$ years, age $<60$ years with amenorrhea for $\geq 12$ months in the absence of CT, tamoxifen, toremifen, or ovarian suppression with $\mathrm{FSH}$ and $\mathrm{E}_{2}$ in the postmenopausal range. If taking tamoxifen or toremifen, and age $<60$ years, $\mathrm{FSH}$ and plasma $\mathrm{E}_{2}$ levels should be within the postmenopausal range (NCCN - Breast Cancer Guidelines 2011).

Menopausal transition typically begins several years before the natural menopause, in the mid-40s, preceding the final menses by $2-8$ years, with a mean duration of 4 years. In this period, the levels of hormones produced by the aging ovaries fluctuate considerably, leading to abnormal menstrual patterns (irregularity in the length of the periods, the time between periods, and the level of flow), hot flashes, night sweats, mood changes, vaginal dryness, fluctuations in libido, forgetfulness, trouble sleeping, fatigue, and weight gain. The endocrine changes underlying menopausal transition are predominantly the consequence of a marked decrease in ovarian follicle numbers. $E_{2}$ levels fall considerably, whereas estrone levels remain almost unchanged, reflecting peripheral aromatization of adrenal and ovarian androgens. The increase in FSH levels is more than that in the $\mathrm{LH}$, presumably because of the loss of inhibins, as well as estrogen feedback. Other significant changes include a decrease in inhibin-B in the early phase of the menstrual cycle and in $\mathrm{AMH}$ levels.

Perimenopause starts with menopausal transition, lasting throughout the 12 months of amenorrhea. 
Table 1 Estimated risk of permanent amenorrhea resulting from single-agent chemotherapy and combination regimens used as adjuvant treatment for early breast cancer, modified from Lee et al. (2006)

\begin{tabular}{|c|c|}
\hline Single drug & Adjuvant regimens \\
\hline $\begin{array}{l}\text { High risk (>80\%) } \\
\text { Cyclophosphamide } \\
\text { Ifosfamide } \\
\text { Chlorambucil } \\
\text { Melphalan, Busulfan } \\
\text { Nitrogen mustard } \\
\text { Procarbazine } \\
\text { Thiotepa }\end{array}$ & $\begin{array}{l}\text { CMF, FEC and FAC } \times \text { six cycles in } \\
\text { women aged } \geq 40 \text { years }\end{array}$ \\
\hline \multicolumn{2}{|l|}{ Intermediate risk } \\
\hline Cisplatin & $\begin{array}{l}\text { CMF, FEC and } \mathrm{FAC} \times \text { six cycles in } \\
\text { women aged } 30-39 \text { years }\end{array}$ \\
\hline Carboplatin & $\begin{array}{l}A C \text { and } E C \times \text { four cycles in women } \\
\text { aged } \geq 40 \text { years }\end{array}$ \\
\hline $\begin{array}{l}\text { Adriamycin } \\
\text { Taxanes }\end{array}$ & Taxane-containing combinations \\
\hline \multicolumn{2}{|c|}{ Low risk $(<20 \%)$ or no risk } \\
\hline Bleomycin & $\begin{array}{l}\mathrm{CMF}, \mathrm{FEC} \text { and } \mathrm{FAC} \times \text { six cycles in } \\
\text { women aged }<30 \text { years }\end{array}$ \\
\hline Dactinomycin & $\begin{array}{l}A C \text { and } E C \times \text { four cycles in women } \\
\text { aged }<40 \text { years }\end{array}$ \\
\hline Vincristine & \\
\hline Vinblastine & \\
\hline Methotrexate & \\
\hline Mercaptopurine & \\
\hline 5-Fluorouracil & \\
\hline $\begin{array}{l}\text { To be determined } \\
\text { Trastuzumab } \\
\text { Lapatinib }\end{array}$ & \\
\hline
\end{tabular}

role of predictive factors of CIA and CIM in women affected by EBC are reviewed.

\section{CT-induced primary ovarian insufficiency}

CT-induced primary ovarian insufficiency (CT-POI) results from an acceleration of the natural ovarian aging process due to damage in steroid-producing cells (granulosa and theca cells) and apoptotic death of a fraction of primordial follicles, mainly impairing follicular development (Fig. 1; Bines et al. 1996, De Vos et al. 2010, Meirow et al. 2010). The sensitivity of the ovaries to cytotoxic drugs varies considerably (Table 1) (Sonmezer \& Oktay 2006), alkylating agents being the most commonly associated with permanent and irreversible gonadal damage (Chapman 1982). For some drugs, such as cyclophosphamide, a direct correlation has been demonstrated between dose intensity and CT-POI (Sonmezer \& Oktay 2006).
The risk of CT-POI has been correlated with the type of CT, higher cumulative doses and older age, age $>40$ years being the strongest predictor of both CIA and CIM (Stearns et al. 2006, Jeruss \& Woodruff 2009, De Vos et al. 2010). In addition, CT regimens administered during the follicular phase of the menstrual cycle may have a greater toxic effect on ovaries (Bines et al. 1996, Di Cosimo et al. 2004, Walshe et al. 2006). Inherited factors have been proposed in playing a key role in the onset of menopause, and emerging data suggest that specific genes may influence the risk of CIA/CIM (Stearns et al. 2006, Su et al. 2010a). In addition, breast cancer per se may increase the risk of POI, in the absence of systemic treatment (Mertens et al. 2001, Partridge \& Ruddy 2007).

The extent and type of damage affect the degrees of subsequent ovarian dysfunction. Whether exposure to CT induces complete follicular depletion or very few follicles remain viable, periods may cease definitively and menopause will occur (Partridge \& Ruddy 2007, Schover 2008). If more follicles survive, women may develop amenorrhea or periods may become irregular (oligomenorrhea) and menopausal symptoms arise. Despite the fact that many patients $>40$ years of age develop CIA, this type of ovarian failure may be temporary in a considerable number of women (Petrek et al. 2006, Sukumvanich et al.2010). The percentage of women with CIA/oligomenorrhea that will later develop CIM is not yet known. Menstrual cycles and/ or fertility may recover months to years after withdrawal of CT. Menses are more likely to return in younger women, in those exposed to less gonadotoxic regimens, and in those with a higher basal number of follicles (Walshe et al. 2006, Schover 2008). In fact, the remaining follicles may regrow in 3-6 months from the primordial pool and gonadotropin levels may return to normal once CT is withdrawn, especially in very younger women (Sonmezer \& Oktay 2006). Women with temporary CIA present an increased risk of premature ovarian failure compared with those who continue to menstruate throughout treatment (Ganz et al. 2003). Short or irregular menstrual cycles also indicate a decrease in ovarian reserve (OR; Oktay et al. 2006).

Very few studies specifically evaluated the rate of CIM in patients with EBC (Padmanabhan et al. 1986, Goodwin et al. 1999). The occurrence of CIM is reported to be in the range of $22-61 \%$ in women $<40$ years and $61-97 \%$ in those $>40$ years (Del Mastro et al. 1997). Higher cumulative doses of alkylating agents in older premenopausal patients and an arbitrary 12-month period of CIA are considered predictive 


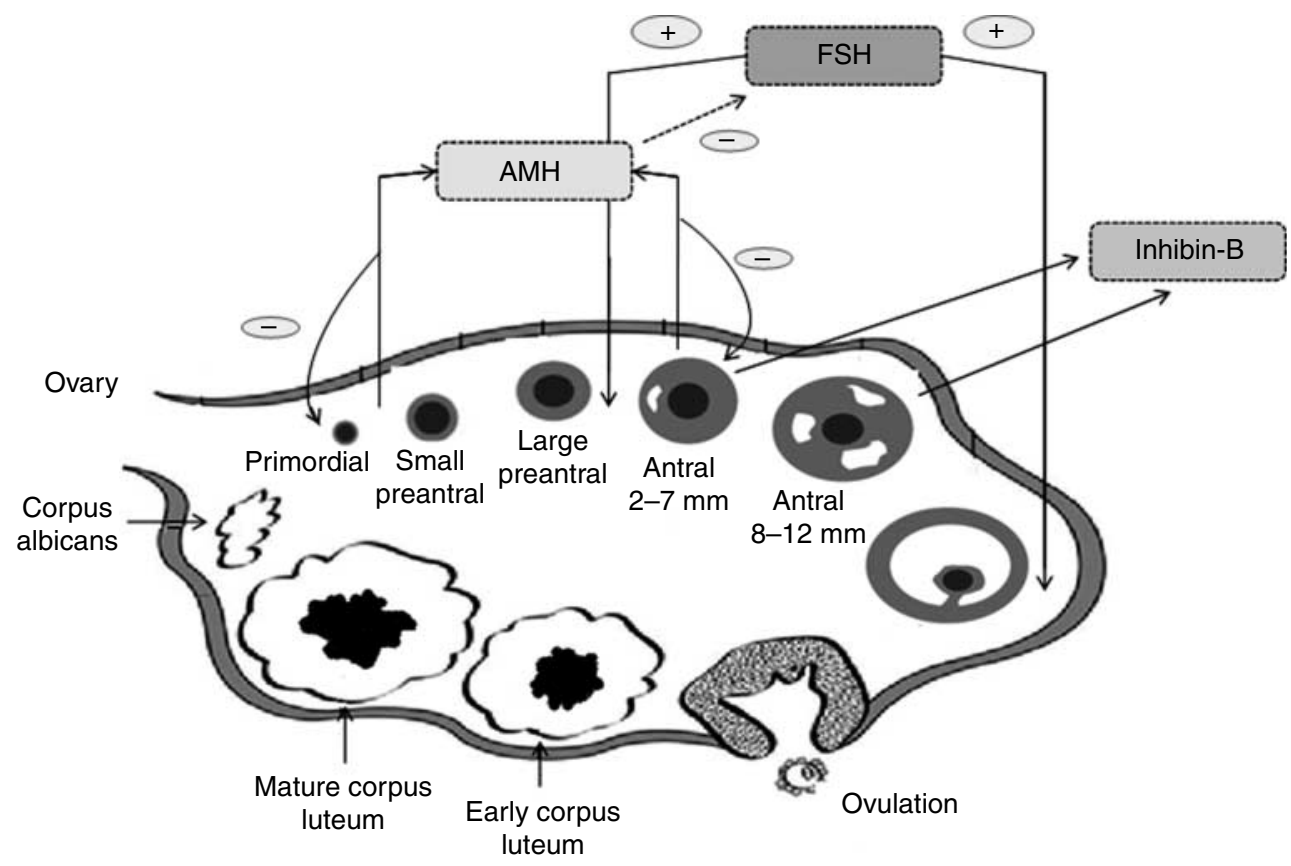

Figure 1 Selective activity of $\mathrm{FSH}, \mathrm{AMH}$, and inhibin-B on folliculogenesis. Initial follicle recruitment is a continuous process, whereas cyclic recruitment is driven by an increase in FSH serum levels at the end of a previous menstrual cycle. AMH is secreted by preantral and antral follicles and appeared to play an inhibiting role in initial recruitment of primary follicles from the resting primordial follicle pool and in the selection of the dominant follicle, by reducing the sensitivity of antral follicles for FSH. Inhibin-B may have paracrine functions positively influencing folliculogenesis (Hillier 1991, Findlay et al. 2000, Visser et al. 2006, Broekmans et al. 2008).

of CIM (Partridge et al. 2007, Tham et al. 2007, Han et al. 2009).

Rates of CIA in premenopausal women receiving a poly-CT regimen for EBC may range from 49 to $100 \%$ in women $>40$ years and from 21 to $71 \%$ in younger women (Goldhirsch et al. 1990, Bines et al. 1996, Goodwin et al. 1999, Basser et al. 2006, Del Mastro et al. 2011). Transient and prolonged amenorrhea was more frequent with CMF- and CEF/CAF-type regimens compared with AC (Bines et al. 1996), presumably due to a higher cumulative dose of cyclophosphamide received. Addition of taxanes has shown to increase the risk of CIA, particularly in the first year, in many (Martin et al. 2005, Tham et al. 2007, Han et al. 2009, Swain et al. 2009, Najafi et al. 2011) but not in all trials (Davis et al. 2005, Fornier et al. 2005, Berliere et al. 2008, Lee et al. 2009, Abusief et al. 2010, Perez-Fidalgo et al. 2010, Zhou et al. 2010). However, comparison of rates of CIA across different studies is limited by considerable differences in treatments used, median age of patients, prevalence of endocrine-responsive disease, follow-up duration, and variability in the definition of CIA (from 3 months to $>1$ year absence of menses).

Tamoxifen, following a CT regimen, led to a significant increase in the rate and/or duration of CIA
(Boccardo et al. 1990, Jordan et al. 1991, Goodwin et al. 1999, Colleoni et al. 2006, Swain et al. 2009, Jung et al. 2010, Ganz et al. 2011) and resulted in a slight but statistically significant increase in the risk of CIM (Bines et al. 1996). However, how tamoxifen influences CIA/CIM remains unclear. It has been suggested that the drug increases plasma estradiol $\left(\mathrm{E}_{2}\right)$ levels and interferes with the hypothalamic-ovarian feedback loop that regulates estrogen synthesis (Rose \& Davis 1980, Rossi et al. 2009, Partridge et al. 2010).

\section{Evaluating $O R$ in cancer patients}

OR refers to the number and quality of follicles that, at any given age, are available to produce a dominant follicle late in the follicular phase of the menstrual cycle. In the fertility setting and assisted reproduction, in order to ascertain the OR, a number of procedures are used (Box 2) (Lambalk et al. 2009). These include ultrasound assessment of the antral follicle count (AFC) and the ovarian volume (OV) as well as blood tests to establish the levels of $\mathrm{FSH}, \mathrm{E}_{2}$, inhibin-B, and anti-Müllerian hormone (AMH). AMH and AFC provide the most reliable assessment of the reproductive lifespan of the ovaries, estimation of fertility status, and risk of premature ovarian failure. Menstrual 


\section{Box 2 Tools available to estimate ovarian reserve and menopause}

Antral follicle count ( $A F C$ ). The most common ultrasound tests to evaluate ovarian reserve (OR) are AFC, ovarian volume (OV), and stromal blood flow. However, only AFC and OV are reliable indicators of OR and potential predictors of menopausal age. However, OV assessment may not be precise and the intercycle variation of OV is more pronounced than that of AFC (Jayaprakasan et al. 2008). Although the results are conflicting, AFC is currently the most reliable ultrasound parameter predicting age at menopause (Lambalk et al. 2009).

FSH. FSH is responsible for follicular recruitment, growth, as well as for androgen conversion to estrogen during folliculogenesis (Fig. 1). Ovarian granulosa cells are the target of FSH. Elevated levels of FSH are the hormonal hallmark of reproductive aging. The Stages of Reproductive Aging Workshop (STRAW) proposed FSH as the best predictive marker of menopause but did not establish the precise cutoff values defining menopausal status (Soules et al. 2001). The early follicular phase FSH values gradually start to increase $\sim 10$ years before menopause, possibly simultaneous with the beginning of reduction in fertility (van Rooij et al. 2005, Sowers et al. 2008a). Low FSH levels (< $20 \mathrm{IU} / \mathrm{l})$, assessed on day 3 of the cycle, indicate a good likelihood of achieving pregnancy and are inconsistent with perimenopause. FSH values $\geq 30 \mathrm{IU} / \mathrm{I}$ indicate poor likelihood of pregnancy while values $\geq 40 \mathrm{IU} / \mathrm{l}$ are indicative of late menopausal transition (van Montfrans et al. 2000). FSH levels are influenced by age and body size, independently of menstrual status. Furthermore, differences in results between assays evaluating serum FSH may have a confounding effect.

Estradiol $\left(E_{2}\right)$. A recent longitudinal follow-up study showed a continuous decline in sex steroids with advancing age (Sowers et al. 2008b). Average $\mathrm{E}_{2}$ levels showed an increase in late menopausal transition, before a rapid decline shortly before menopause occurred $(20 \mathrm{pg} / \mathrm{ml})$ (Gracia et al. 2005).

$\mathrm{LH}$. LH levels increase with age as a result of increased pituitary sensitivity to $\mathrm{GnRH}$, independently of $\mathrm{E}_{2}$ levels (de Koning et al. 2000). During menopausal transition, LH rises slowly, reaching moderately elevated levels in postmenopause. The increase in FSH levels is more than that in $\mathrm{LH}$, presumably because of the loss of inhibin-B as well as estrogen feedback.

Inhibins and activins. These hormones are members of the transforming growth factor B (TGF- $\beta$ ) superfamily. Both inhibin-A and -B directly suppress pituitary FSH secretion, while activins selectively stimulate FSH secretion (Hillier 1991, Findlay et al. 2000). Inhibin-B may also have paracrine functions influencing folliculogenesis in the ovary (Fig. 1) (Hillier 1991, Findlay et al. 2000). Little evidence has so far been obtained supporting a role for activins in FSH regulation during menopausal transition (Lambalk et al. 2009). Inhibin-A, secreted primarily by the mature follicle and corpus luteum, suppresses FSH secretion (Roberts et al. 1993). In some cross-sectional studies, inhibin-A levels appeared lower in older women but at a later stage of menopausal transition (Lambalk et al. 2009).

Inhibin-B is a product of the smaller nondominant antral follicles and, as such, reflects the ovarian follicle pool (Hall et al. 1999). Serum inhibin-B levels decrease to very low or undetectable levels about 4 years before the last menstrual period (Sowers et al. 2008a). In longitudinal studies, inhibin-B correlates with age only during a relatively short time before menopausal transition (van Rooij et al. 2005). Inhibin-B is probably a better indicator of ovarian activity than OR, due to its direct link with growing follicles. Inhibin-B is influenced by fluctuating ovarian function of late ovarian aging and throughout the menstrual cycle. Inhibin-B seems not to be affected by the concomitant use of tamoxifen (Su et al. 2010b).

Anti-Müllerian hormone $(A M H)$. AMH, also known as Müllerian-inhibiting substance, is another member of the TGF- $\beta$ superfamily. AMH is produced by the Sertoli cells of the testis in the male and by ovarian granulosa cells of preantral and small antral follicles in the adult female, the number of which is related to the size of the primordial follicle pool (Broekmans et al. 2008). AMH modulates primordial follicle recruitment and inhibits cyclic follicle recruitment for folliculogenesis, mainly by inhibiting the action of FSH on follicle growth and selection (Themmen 2005, Broekmans et al. 2008). In the female, serum AMH is undetectable until the onset of puberty. AMH is considered to reflect the nonFSH-dependent follicular growth (La Marca et al. 2007). As a follicle matures, AMH production disappears allowing the follicle to complete the development process during the FSH-dependent stages of growth (Visser et al. 2006). AMH secretion is independent of other hormones and is expressed at a constant level, irrespective of the day of the menstrual cycle (Cook et al. 2000). AMH levels show a progressive and linear decline until menopause, this being attributed to a decreasing number of primordial pool follicles (van Rooij et al. 2005, van Disseldorp et al. 2008). Healthy perimenopausal women showed a linear decline in AMH profiles to values below detection 5 years before the final menstrual period, whereas mean serum $\mathrm{E}_{2}$ levels were maintained until $\sim 2$ years before the final menstrual period (Sowers et al. 2008b). 
$\mathrm{AMH}$ is more strongly related to AFC than other biomarkers, thus reflecting the quantity of follicles and the quality of oocytes (Visser et al. 2006). Therefore, AMH may be used as a direct measure of OR and is considered the best single predictor of poor response to assisted reproductive techniques (La Marca et al. 2009). When women with a normal reproduction activity were examined, during an average time of 4 years, which included AFC and various hormonal markers, serum AMH, followed by AFC, showed the most consistent correlation to the age-related decline in reproductive capacity (van Rooij et al. 2004).

Specific nomograms are available to individually calculate, using age and $\mathrm{AMH}$, the age range in which menopause will subsequently occur both for normo-ovulatory women and for reproductive likelihood of infertility patients (Broer et al. 2011, Nelson et al. 2011).

Menstrual cycle changes. Shortening of menstrual cycle duration, multiple follicle growth, and anovulation are key features of reproductive aging (Van Voorhis et al. 2008). However, these changes occur relatively late and are not reliable predictors of menopause. At present, the occurrence of vasomotor symptoms is held to predict the final menstrual period within $\sim 2$ years (Lambalk et al. 2009).

cycle irregularity, vasomotor symptoms, very high basal FSH, and undetectable inhibin-B levels have been shown to be the only short-term predictors of menopause (within 2 years) (Lambalk et al. 2009). Low/undetectable levels of AMH, low AFC, a poor response to in vitro follicle stimulation, and rise in the early follicular phase of FSH indicate a limited OR and earlier menopause in later life but do not predict imminent menopause (Lambalk et al. 2009).

In patients exposed to anticancer treatments, the above mentioned tests are routinely used to assess residual OR and predict outcome in assisted reproduction (Oktay et al. 2006, Lutchman Singh et al. 2007, Partridge et al. 2010). To this end, AMH is the most promising marker of OR (Schover 2008). Compared with FSH and inhibin-B, AMH was the most sensitive predictor for OR in women treated with CT for Hodgkin's lymphoma, in younger women who had received CT/radiotherapy for childhood cancer (Bath et al. 2003: van Beek et al. 2007, Lie Fong et al. 2009), and in premenopausal patients affected by EREBC receiving adjuvant CT/ET (Anderson \& Cameron 2011).

\section{Recognizing menopause in women affected by EBC and CIA}

Certain clinical features (age, menstrual history, and menopausal symptoms) are generally indicative of menopausal status, which may be confirmed by the presence of serum levels of FSH and $E_{2}$ within the menopausal range. These parameters, however, are not completely reliable to confirm menopause. Furthermore, the definition of menopause is not consistent across studies that have assessed ovarian function following CT (Clemons \& Simmons 2007). In most of these reports, cessation of menses was the only surrogate marker of menopause, and the duration of the follow-up period was limited. National Cancer
Comprehensive Network (NCCN) guidelines defined some criteria for diagnosing menopause in breast cancer patients (Box 1) (NCCN - Breast Cancer Guidelines 2011). Moreover, it was emphasized that for premenopausal women starting adjuvant ET, CIA is not a reliable indicator of menopausal status, as ovarian function may still be preserved or resume despite CT-induced anovulation/amenorrhea. Serial measurements of $\mathrm{FSH} / \mathrm{E}_{2}$ are recommended in patients with $\mathrm{CIA}$, if treatment with $\mathrm{AI}$ is foreseen (NCCN - Breast Cancer Guidelines 2011).

AIs are a standard treatment option for postmenopausal women with EREBC (Burstein et al. 2010, Goldhirsh et al. 2011). It has been reported that pre/ perimenopausal women at the time of diagnosis who became amenorrheic following adjuvant CT may have received an AI as monotherapy, if they had shown FSH/E $\mathrm{E}_{2}$ levels within menopausal range (Burstein et al. 2006, Smith et al. 2006). The inappropriate use of AI in premenopausal women induces a temporary inhibition of estrogen production, leading to a feedback increase in gonadotropin levels, which, in turn, stimulate follicular growth, aromatase production, and restoration of pre-CT $\mathrm{E}_{2}$ levels (de Ziegler et al. 2005). These changes in hormonal levels would be expected to reduce or abolish the efficacy of the anticancer treatment received, and to expose further unjustified side effects, including pain from ovarian hyperstimulation and increased risk of unplanned pregnancy (Smith et al. 2006). Therefore, AIs as single agents are contraindicated in premenopausal women, and confirmation of the menopausal status is mandatory before starting these drugs (Ortmann et al. 2011).

Elevated FSH and reduced $\mathrm{E}_{2}$ levels generally confirm the clinical diagnosis of menopause. However, biochemical tests present a number of limits. The transition toward menopause is highly variable, as it is a dynamic continuum, and a diagnostic cutoff of these 
biomarkers would be difficult to define. Therefore, testing for $\mathrm{FSH} / \mathrm{E}_{2}$ only at a single point of time is not sufficient to confirm menopause. In this respect, repeated measurement of these biomarkers, at more than one time point, would be more reliable. However, the number of timepoints to be collected and the duration of the collection intervals are arbitrary. In addition, some technical aspects may negatively affect reliability of biochemical tests. Current plasma $\mathrm{E}_{2}$ RIA is not sufficiently sensitive to detect the low postmenopause $\mathrm{E}_{2}$ levels (Wang et al. 2005). Tandem mass spectrometry, a validated method used for dosing steroids in the picogram/milliliter range, is not widely available in nonresearch settings (Sundaram et al. 2003, Smith et al. 2006). Furthermore, tamoxifen has been reported to increase circulating estrogens and decrease FSH levels (Rossi et al. 2009). AIs have been shown to profoundly decrease estrogens and increase FSH levels in postmenopausal patients (Rossi et al. 2009). Increased levels of $E_{2}$ induced by tamoxifen may be related to cross-reactivity of tamoxifen and its metabolites in the $\mathrm{E}_{2}$ assay (Rossi et al. 2009). Likewise, exemestane, a steroidal AI, may interfere with serum $\mathrm{E}_{2}$ measurement (Johannessen et al. 1997). Therefore, in this clinical setting, amenorrhea and $\mathrm{FSH} / \mathrm{E}_{2}$ levels remain inaccurate surrogate markers of menopause (Amir et al. 2009).
Interestingly, in a few studies on a limited cohort of patients who received adjuvant CT for EREBC, prechemotherapy AMH (Anderson et al. 2006) or AMH and inhibin-B (Anders et al. 2008, Su et al. $2010 b$ ) were significantly lower in women who experienced CIA, a predictive of CIA. These results, however, have not been confirmed in another retrospective study (Yu et al. 2010). Also, the influence of tamoxifen on AMH and inhibin-B has been studied, but conflicting results have been reported (Anderson et al. 2006, Partridge et al. 2010, Su et al. 2010b).

Unfortunately, due to some limitations in these studies, it is not possible to define the role of these new markers of OR as predictive factors of CIM in clinical practice. In fact, none of these studies have been specifically designed to test $\mathrm{AMH} / \mathrm{inhibin}-\mathrm{B}$ as predictive factors of CIM; duration of follow-up, and cohorts of patients are limited; the age distribution among the cohorts, the treatment received, and sample collection time appear inhomogeneous.

Very recently, in a prospective study, with a 5-year median follow-up, basal serum AMH was reported to be strongly predictive of long-term ovarian function in a cohort of 42 patients undergoing CT (and/or ET) for $\mathrm{EBC}$. In particular, AMH remained the only significant predictive factor of late OR in a multivariate analysis including age and FSH (Anderson \& Cameron 2011).

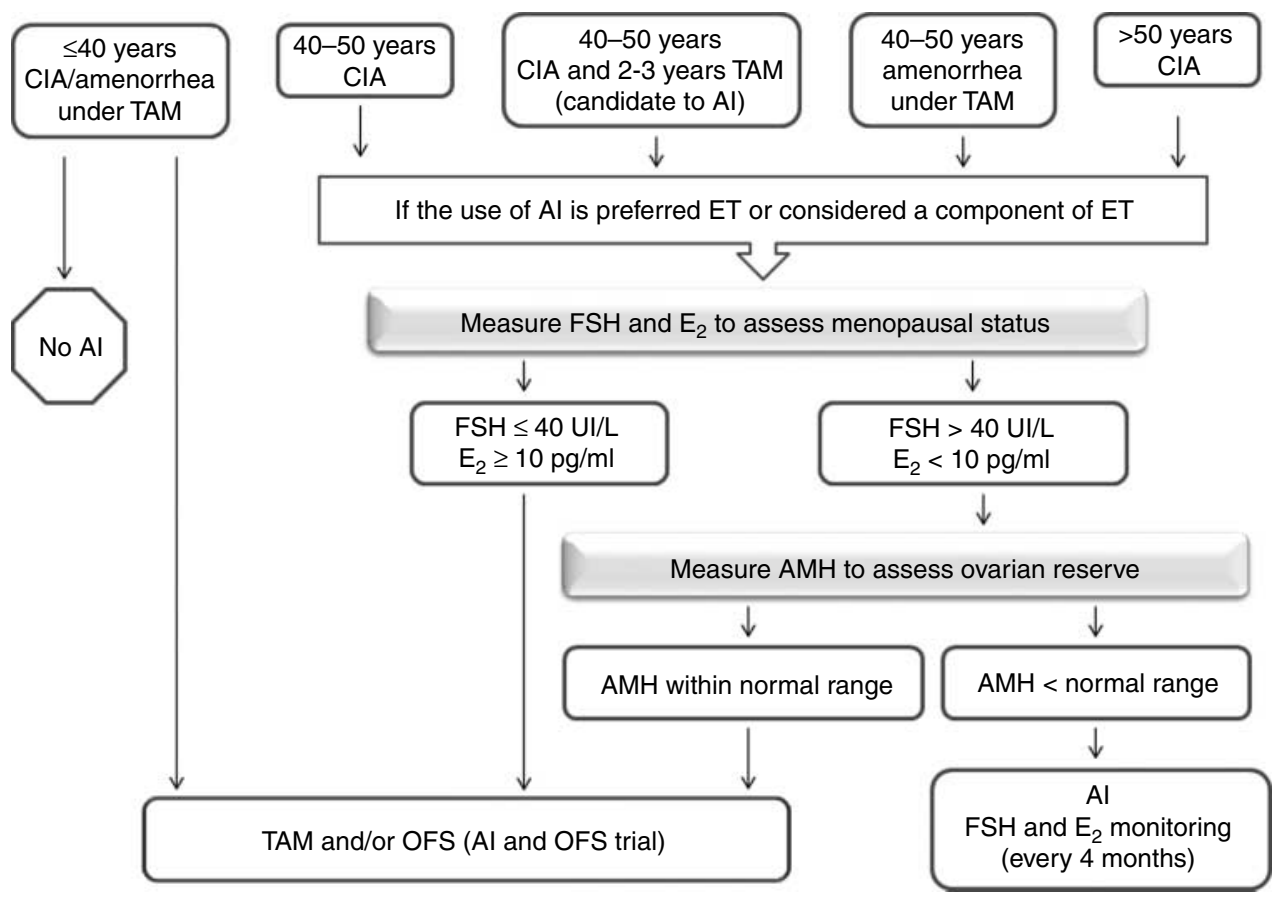

Figure 2 Practical approaches suggested whether Als are considered as ET in women with EREBC and CIA or amenorrhea under TAM. Al, aromatase inhibitor; $\mathrm{AMH}$, anti-Müllerian hormone; $\mathrm{CIA}$, chemotherapy-induced amenorrhea; $\mathrm{E}_{2}$, estradiol; EREBC, endocrine-responsive early breast cancer; ET, endocrine therapy; OFS, ovarian function suppression; TAM, tamoxifen. 
At present, $\mathrm{AFC}, \mathrm{AMH}$, and inhibin-B are reliable predictive factors of fertility even in cancer patients. Moreover, AMH appears to be the most promising tool to improve the assessment of CIM (Schover 2008, Anderson \& Cameron 2011).

\section{Practical approaches}

In premenopausal women presenting amenorrhea following adjuvant CT for EBC, the diagnosis of menopause still remains difficult.

The likelihood of resuming ovarian function decreases as a woman approaches the mean age of natural menopause (51 years) and when more ovarian toxic agents are included in CT regimens. However, the individual risk of CIM cannot be predicted. To this end, a prechemotherapy evaluation of OR may offer another predictive element (Oktay et al. 2006, Rosendahl et al. 2010) to be compared later with a postchemotherapy OR assessment.

The choice of adjuvant ET may be guided by age only in a specific group of patients (Fig. 2). Women $\leq 40$ years with CIA should not receive an AI as the only adjuvant ET. If in these patients estrogen depletion is the desired endocrine strategy, this should include OFS (oophorectomy or chemical ovarian suppression with a GnRH agonist) in combination with tamoxifen (Burstein et al. 2010, Goldhirsh et al. 2011, NCCN - Breast Cancer Guidelines 2011).

amoxifen and/or OFS should be considered the standard of care even in women aged 40-50 years, who were pre/perimenopausal at the time of starting adjuvant $\mathrm{CT}$ for EREBC. In these patients, and even in those older than 50 years, if an $\mathrm{AI}$ is considered to be a better option, the most accurate definition of the true menopausal status is mandatory. There is some new evidence that $\mathrm{AMH}$ may reveal the residual activity of ovarian function in women with CIA (Anderson \& Cameron 2011). In our opinion, the use of $\mathrm{AMH}$, in conjunction with an endocrinology consult, if needed, may support and strengthen the information obtainable from high-quality assessment of $\mathrm{E}_{2}$ and $\mathrm{FSH}$.

Accordingly, women between 40 and 50 years of age who have developed CIA should preferably be evaluated in a laboratory where a high-quality $\mathrm{E}_{2}$ assay is available, in order to obtain the most accurate monitoring of serial $E_{2}$ together with gonadotropin levels. Women who have levels within the premenopausal range (i.e. $\mathrm{FSH} \leq 40 \mathrm{IU} / \mathrm{l}$ and $\mathrm{E}_{2} \geq 10 \mathrm{pmol} / \mathrm{l}$ ) should receive tamoxifen alone, or tamoxifen together with OFS. Another option is to participate in a clinical trial evaluating the combination of an AI with OFS. If hormone levels indicate the presence of a postmenopausal status (i.e. FSH $>40 \mathrm{IU} / 1$ and $\mathrm{E}_{2}$ $<10 \mathrm{pmol} / \mathrm{l})$, AMH assessment may be useful in order to ascertain residual ovarian function (Anderson \& Cameron 2011). If AMH levels are below the lower limits of normal range, AI may be cautiously started. In addition, despite the known limitations, serial hormone monitoring should be performed (with a reasonable timing of 4 months between two consecutive measurements) to achieve an ongoing confirmation of menopausal status (Fig. 2). If levels remain in postmenopausal range, AI can be continued. Conversely, tamoxifen (and/or OFS) is the appropriate ET.

The same approach should be used in premenopausal women $>40$ years with CIA who may start AI after 2-3 years of treatment with tamoxifen.

Likewise, in women who develop amenorrhea during tamoxifen treatment, irrespective of previous $\mathrm{CT}$, and who are considered as candidates for switching to an AI, it is advisable to perform serial highquality evaluations of $\mathrm{E}_{2}$ together with $\mathrm{FSH}$ and AMH. Only in the case of confirmed menopausal findings, the shift can be safely made.

Women over 50 years of age at the time of CT and with CIA lasting $\geq 6$ months may receive $\mathrm{AI}$ if the hormone assessment has provided enough certainty of menopause. However, if a continuous rise in $\mathrm{E}_{2}$ levels is documented, tamoxifen should replace AI.

It should be emphasized that amenorrhea alone is always a poor surrogate for ovarian function, and CIA may be transient and reversible, especially in younger women. Therefore, all pre/perimenopausal women with CIA, particularly the ones receiving an AI, should be instructed to inform their clinician if vaginal bleeding occurs or hot flashes suddenly stop (Smith et al. 2006). Furthermore, sexually active women require counseling regarding the need to maintain birth control, because they may still ovulate and become pregnant, even when they are not menstruating. Finally, despite the fact that resumption of ovarian function with an $\mathrm{AI}$ is anecdotic, even when women are receiving a GnRH agonist, a barrier contraception method should be recommended and practiced during the monitoring period or, alternatively, ovarian surgical ablation may be proposed (Smith et al. 2006).

\section{Conclusions}

The risk of premature iatrogenic menopause should be taken into consideration when assisting younger women with their anticancer treatment and familyplanning decisions, both at diagnosis and during the follow-up. Evaluation of residual ovarian function 
following adjuvant $\mathrm{CT}$ may be challenging and the availability of better predictors providing more reliable assessments of OR is of particular relevance in patients with EREBC, as AI lead to improvements in survival of those who are postmenopausal. However, in these patients, tamoxifen should be considered the standard of care until menopause can be confirmed, even in women between ages 40 and 50 years, unless OFS is being induced. AMH, inhibin-B, FSH, $\mathrm{E}_{2}, \mathrm{AFC}$, and $\mathrm{OV}$ are currently used to estimate the OR in women with POI and CT-POI. The basal assessment of OR may identify the true reproduction potential of a woman before starting a cytotoxic regimen and thus allow timely planning of appropriate fertility-preservation procedures (Lee et al. 2006, Oktay et al. 2006). Moreover, the posttreatment evaluation of OR, compared with basal assessment, may be useful to evaluate residual OR and indirectly offer the clinician the opportunity to estimate the onset of menopause in women with CIA. However, this is a stimulating hypothesis that would require confirmation through appropriately designed clinical studies. Prospective trials on a large number of patients, aimed at correlating the available OR parameters with the exact time of the last menstrual period, would then define their role in predicting the menopausal status of women with EREBC and CIA and, therefore, provide reliable information that would be helpful in the selection of the most suitable ET for these patients. Meanwhile, rational and careful use of the best predictors of $\mathrm{OR}$, in particular $\mathrm{AMH}$, may be useful in prescribing the most appropriate ET for these patients. A close collaboration between endocrinologists and oncologists may help in properly implementing the above diagnostic tools in daily clinical practice.

\section{Declaration of interest}

The authors declare that there is no conflict of interest that could be perceived as prejudicing the impartiality of the review reported.

\section{Funding}

This review did not receive any specific grant from any funding agency in the public, commercial or not-for-profit sector.

\section{Acknowledgements}

All the authors are thankful to Maria Alba, MD, for the valuable discussions and suggestions and Marian Elizabeth Shields for language revision of the manuscript.

\section{References}

Abusief ME, Missmer SA, Ginsburg ES, Weeks JC \& Partridge AH 2010 The effects of paclitaxel, dose density, and trastuzumab on treatment-related amenorrhea in premenopausal women with breast cancer. Cancer 116 791-798. (doi:10.1002/cncr.24835)

Amir E, Seruga B, Freedman OC \& Clemons M 2009 Endocrine therapy for breast cancer: prolonged amenorrhoea is not necessarily indicative of menopause. $B M J$ 339 b4261. (doi:10.1136/bmj.b4261)

Anders C, Marcom PK, Peterson B, Unruhe S, Welch R, Lyons P, Behera M, Copland S, Kimmick G, Shaw H et al. 2008 A pilot study of predictive markers of chemotherapy-related amenorrhea among premenopausal women with early stage breast cancer. Cancer Investigation 26 286-295. (doi:10.1080/07357900701829777)

Anderson RA \& Cameron DA 2011 Pretreament serum antiMullerian hormone predicts long-term ovarian function and bone mass after chemotherapy for early breast cancer. Journal of Clinical Endocrinology and Metabolism 96 1336-1343. (doi:10.1210/jc.2010-2582)

Anderson RA, Themmen AP, Al-Qahtani A, Groome NP \& Cameron DA 2006 The effects of chemotherapy and longterm gonadotrophin suppression on the ovarian reserve in premenopausal women with breast cancer. Human Reproduction 21 2583-2592. (doi:10.1093/humrep/del201)

Basser RL, O’Neill A, Martinelli G, Green MD, Peccatori F, Cinieri S, Coates AS, Gelber RD, Aebi S, CastiglioneGertsch M et al. 2006 Multicycle dose-intensive chemotherapy for women with high-risk primary breast cancer: results of International Breast Cancer Study Group Trial 15-95. Journal of Clinical Oncology 24 370-378. (doi:10.1200/JCO.2005.03.5196)

Bath LE, Wallace WH, Shaw MP, Fitzpatrick C \& Anderson RA 2003 Depletion of ovarian reserve in young women after treatment for cancer in childhood: detection by antiMüllerian hormone, inhibin B and ovarian ultrasound. Human Reproduction 18 2368-2374. (doi:10.1093/ humrep/deg473)

van Beek RD, van den Heuvel-Eibrink MM \& Laven JS 2007 Anti-Mullerian hormone is a sensitive serum marker for gonadal function in women treated for Hodgkin's lymphoma during childhood. Journal of Clinical Endocrinology and Metabolism 92 3869-3874. (doi:10. 1210/jc.2006-2374)

Berliere M, Dalenc F, Malingret N, Vindevogel A, Piette P, Roche H, Donnez J, Symann M, Kerger J \& Machiels JP 2008 Incidence of reversible amenorrea in women with breast cancer undergoing adjuvant anthracycline-based chemotherapy with or without docetaxel. BMC Cancer $\mathbf{8}$ 56. (doi:10.1186/1471-2407-8-56)

Bines J, Oleske D \& Cobleigh M 1996 Ovarian function in premenopausal women treated with adjuvant chemotherapy for breast cancer. Journal of Clinical Oncology 14 1718-1729.

Boccardo F, Rubagotti A, Bruzzi P, Cappellini M, Isola G, Nenci I, Piffanelli A, Scanni A, Sismondi P, Santi L et al. 
1990 Chemotherapy versus tamoxifen versus chemotherapy plus tamoxifen in node-positive, estrogen receptorpositive breast cancer patients: results of a multicentric Italian study. Breast Cancer Adjuvant Chemo-Hormone Therapy Cooperative Group. Journal of Clinical Oncology 8 1310-1320.

Broekmans FJ, Visser JA, Laven JS, Broer SL, Themmen AP \& Fauser BC 2008 Anti-Mullerian hormone and ovarian dysfunction. Trends in Endocrinology and Metabolism 19 340-347. (doi:10.1016/j.tem.2008.08.002)

Broer SL, Eijkemans MJ, Scheffer GJ, van Rooij IA, de Vet A, Themmen AP, Laven JS, de Jong FH, Te Velde ER, Fauser BC et al. 2011 Anti-Mullerian hormone predicts menopause: a long-term follow-up study in normoovulatory women. Journal of Clinical Endocrinology and Metabolism 96 2532-2539. (doi:10.1210/jc.2010-2776)

Burstein HJ, Mayer E, Patridge AH, O'Kane H, Litsas G, Come SE, Hudis CA, Goldstein DF, Muss HB, Winter EP et al. 2006 Inadvertent use of aromatase inhibitors in patients with breast cancer with residual ovarian function: cases and lessons. Clinical Breast Cancer 71 58-161.

Burstein HJ, Prestrud AA, Seidenfeld J, Anderson H, Buchholz TA, Davidson NE, Gelmon KE, Giordano SH, Hudis CA, Malin J et al. 2010 American Society of Clinical Oncology clinical practice guideline: update on adjuvant endocrine therapy for women with hormone receptor-positive breast cancer. Journal of Clinical Oncology 28 3784-3796. (doi:10.1200/JCO.2009.26. 3756)

Chapman R 1982 Effect of cytotoxic therapy on sexuality and gonadal function. Seminars in Oncology 9 84-94.

Clemons M \& Simmons C 2007 Identifying menopause in breast cancer patients: considerations and implications. Breast Cancer Research and Treatment 104 115-120. (doi:10.1007/s10549-006-9401-y)

Colleoni M, Gelber S, Goldhirsch A, Aebi S, CastiglioneGertsch M, Price KN, Coates AS \& Gelber RD 2006 Tamoxifen after adjuvant chemotherapy for premenopausal women with lymph node-positive breast cancer: International Breast Cancer Study Group Trial 13-93. Journal of Clinical Oncology 24 1332-1341. (doi:10.1200/JCO.2005.03.0783)

Cook CL, Siow Y, Taylor S \& Fallat ME 2000 Serum mullerian-inhibiting substance levels during normal menstrual cycles. Fertility and Sterility 73 859-861. (doi:10.1016/S0015-0282(99)00639-1)

Davis AL, Klitus M \& Mintzer DM 2005 Chemotherapyinduced amenorrhea from adjuvant breast cancer treatment: the effect of the addition of taxanes. Clinical Breast Cancer 6 421-424. (doi:10.3816/CBC.2005.n.046)

De Vos M, Devroey P \& Fauser BCJM 2010 Primary ovarian insufficiency. Lancet 376 911-921. (doi:10.1016/S01406736(10)60355-8)

Del Mastro L, Venturini M, Sertoli MR \& Rosso R 1997 Amenorrhea induced by adjuvant chemotherapy in early breast cancer patients: prognostic role and clinical implications. Breast Cancer Research and Treatment 43 183-190. (doi:10.1023/A:1005792830054)

Del Mastro L, Giraudi S, Levaggi A \& Pronzato P 2011 Medical approaches to preservation of fertility in female cancer patients. Expert Opinion on Pharmacotherapy 12 387-396. (doi:10.1517/14656566.2011.522568)

Di Cosimo S, Alimonti A, Ferretti G, Sperduti I, Carlini P, Papaldo P, Fabi A, Gelibter A, Ciccarese M, Giannarelli D et al. 2004 Incidence of chemotherapy-induced amenorrhea depending on the timing of treatment by menstrual cycle phase in women with early breast cancer. Annals of Oncology 15 1065-1071.

van Disseldorp J, Faddy MJ, Themmen AP, de Jong FH, Peeters PH, van der Schouw YT \& Broekmans FJ 2008 Relationship of serum antiMüllerian hormone concentration to age at menopause. Journal of Clinical Endocrinology and Metabolism 93 2129-2134. (doi:10. 1210/jc.2007-2093)

Early Breast Cancer Trialists' Collaborative Group 2005 Effects of chemotherapy and hormonal therapy for early breast cancer on recurrence and 15-year survival: an overview of the randomised trials. Lancet 365 1687-1717. (doi:10.1016/S0140-6736(05)66544-0)

Findlay JK, Drummond AE, Britt KL, Dyson M, Wreford NG, Robertson DM, Groome NP, Jones ME \& Simpson ER 2000 The roles of activins, inhibins and estrogen in early committed follicles. Molecular and Cellular Endocrinology 163 81-87. (doi:10.1016/S0303-7207 (99)00243-9)

Fornier MN, Modi S, Panageas KS, Norton L \& Hudis C 2005 Incidence of chemotherapy-induced, long-term amenorrhea in patients with breast carcinoma age 40 years and younger after adjuvant anthracycline and taxane. Cancer 104 1575-1579. (doi:10.1002/cncr.21385)

Ganz PA, Greendale GA, Petersen L, Kahn B \& Bower JE 2003 Breast cancer in younger women: reproductive and late health effects of treatment. Journal of Clinical Oncology 21 4184-4193. (doi:10.1200/JCO.2003.04.196)

Ganz PA, Land SR, Geyer CE Jr, Cecchini RS, Costantino JP, Pajon ER, Fehrenbacher L, Atkins JN, Polikoff JA, Vogel VG et al. 2011 Menstrual history and quality-of-life outcomes in women with node-positive breast cancer treated with adjuvant therapy on the NSABP B-30 trial. Journal of Clinical Oncology 29 1110-1117. (doi:10. 1200/JCO.2010.29.7689)

Goldhirsch A, Gelber RD \& Castiglione M 1990 The magnitude of endocrine effects of adjuvant chemotherapy for premenopausal breast cancer patients. The International Breast Cancer Study Group. Annals of Oncology 1 183-188.

Goldhirsh A, Wood WC, Coates AS, Gelber RD, Thürlimann B, Senn HJ \& Panel members 2011 Strategies for subtypes - dealing with the diversity of breast cancer: highlights of the St Gallen International Expert Consensus on the Primary Therapy of Early Breast Cancer. Annals of Oncology 22 1736-1747. (doi:10.1093/annonc/mdr304) 
Goodwin PJ, Pritchard KI, Trudeau M \& Hood N 1999 Risk of menopause during the first year after breast cancer diagnosis. Journal of Clinical Oncology 17 2365-2370.

Gracia CR, Sammel MD, Freeman EW, Lin H, Langan E, Kapoor S \& Nelson DB 2005 Defining menopause status: creation of a new definition to identify the early changes of the menopausal transition. Menopause 12 128-135. (doi:10.1097/00042192-200512020-00005)

Hall JE, Welt CK \& Cramer DW 1999 Inhibin A and inhibin B reflect ovarian function in assisted reproduction but are less useful at predicting outcome. Human Reproduction 14 409-415. (doi:10.1093/humrep/14.2.409)

Han HS, Lee KS, Nam BH, Seo JA, Lee DH, Lee H, Lee ES, Kang HS \& Kim SW 2009 Analysis of chemotherapyinduced amenorrhea rates by three different anthracycline and taxane containing regimens for early breast cancer. Breast Cancer Research and Treatment 115 335-342. (doi:10.1007/s10549-008-0071-9)

Hillier SG 1991 Regulatory functions for inhibin and activin in human ovaries. Journal of Endocrinology 131 171-175. (doi:10.1677/joe.0.1310171)

Jayaprakasan K, Campbell B, Hopkisson J, Clewes J, Johnson I \& Raine-Fenning N 2008 Establishing the intercycle variability of three-dimensional ultrasonographic predictors of ovarian reserve. Fertility and Sterility 90 2126-2132. (doi:10.1016/j.fertnstert.2007.10. 028)

Jemal A, Siegel R, Xu J \& Ward E 2010 Cancer statistics, 2010. CA: A Cancer Journal for Clinicians 60 277-300. (doi:10.3322/caac.20073)

Jeruss JS \& Woodruff TK 2009 Preservation of fertility in patients with cancer. New England Journal of Medicine 360 902-911. (doi:10.1056/NEJMra0801454)

Johannessen DC, Engan T, Di Salle E, Zurlo MG, Paolini J, Ornati G, Piscitelli G, Kvinnsland S \& Lonning PE 1997 Endocrine and clinical effects of exemestane (PNU155971), a novel steroidal aromatase inhibitor, in postmenopausal breast cancer patients: a phase I study. Clinical Cancer Research 3 1101-1108.

Jordan VC, Fritz NF, Langan-Fahey S, Thompson M \& Tomey DC 1991 Alteration of endocrine parameters in premenopausal women with breast cancer during longterm adjuvant therapy with tamoxifen as the single agent. Journal of the National Cancer Institute 83 1488-1491. (doi:10.1093/jnci/83.20.1488)

Jung M, Shin HJ, Rha SY, Jeung HC, Hong S, Moon YW, Kim HS, Oh KJ, Yang WI, Roh JK et al. 2010 The clinical outcome of chemotherapy-induced amenorrhea in premenopausal young patients with breast cancer with longterm follow-up. Annals of Surgical Oncology 17 3259-3268. (doi:10.1245/s10434-010-1172-3)

Knauff E, Eijkemans M, Lambalk C, ten Kate-Booij MJ, Hoek A, Beerendonk CC, Laven JS, Goverde AJ, Broekmans FJ, Themmen AP et al. 2009 Anti Mullerian hormone, inhibin B, and antral follicle count in young women with ovarian failure. Journal of Clinical Endocrinology and Metabolism 94 786-792. (doi:10.1210/jc. 2008-1818)

de Koning CH, Popp-Snijders C, Schoemaker J \& Lambalk CB 2000 Elevated FSH concentrations in imminent ovarian failure are associated with higher FSH and LH pulse amplitude and response to GnRH. Human Reproduction 15 1452-1456. (doi:10.1093/humrep/15.7. 1452)

La Marca A, Giulini S, Tirelli A, Bertucci E, Marsella T, Xella S \& Volpe A 2007 Anti-Müllerian hormone measurement on any day of the menstrual cycle strongly predicts ovarian response in assisted reproductive technology. Human Reproduction 22 766-771. (doi:10. 1093/humrep/del421)

La Marca A, Broekmans FJ, Volpe A, Fauser BC \& Macklon NS 2009 Anti-Mullerian hormone (AMH): what do we still need to know. Human Reproduction 24 2264-2275. (doi:10.1093/humrep/dep210)

Lambalk CB, van Disseldorp J, de Koning CH \& Broekmans FJ 2009 Testing ovarian reserve to predict age at menopause. Maturitas 63 280-291. (doi:10.1016/j. maturitas.2009.06.007)

Lee SJ, Schover LR, Partridge AH, Patrizio P, Wallace WH, Hagerty K, Beck LN, Brennan LV \& Oktay K 2006 American Society of Clinical Oncology recommendations on fertility preservation in cancer patients. Journal of Clinical Oncology 24 2917-2931. (doi:10.1200/JCO. 2006.06.5888)

Lee S, Kil WJ, Chun M, Jung YS, Kang SY, Kang SH \& Oh YT 2009 Chemotherapy-related amenorrhea in premenopausal women with breast cancer. Menopause 16 98-103. (doi:10.1097/gme.0b013e3181844877)

Lie Fong S, Laven JS, Hakvoort-Cammel FG, Schipper I, Visser JA, Themmen AP, de Jong FH \& van den HeuvelEibrink MM 2009 Assessment of ovarian reserve in adult childhood cancer survivors using anti-Müllerian hormone. Human Reproduction 24 982-990. (doi:10.1093/ humrep/den487)

Lutchman Singh K, Muttukrishna S, Stein RC, McGarrigle HH, Patel A, Parikh B, Groome NP, Davies MC \& Chatterjee R 2007 Predictors of ovarian reserve in young women with breast cancer. British Journal of Cancer 96 1808-1816. (doi:10.1038/sj.bjc.6603814)

Martin M, Pienkowski T, Mackey J, Pawlicki M, Guastalla JP, Weaver C, Tomiak E, Al-Tweigeri T, Chap L, Juhos E et al. 2005 Adjuvant docetaxel for node-positive breast cancer. New England Journal of Medicine 352 2302-2313. (doi:10.1056/NEJMoa043681)

Meirow D, Biederman H, Anderson RA \& Wallace WH 2010 Toxicity of chemotherapy and radiation on female reproduction. Clinical Obstetrics and Gynecology 53 727-739. (doi:10.1097/GRF.0b013e3181f96b54)

Mertens A, Yasui Y, Neglia J, Potter JD, Nesbit ME Jr, Ruccione K, Smithson WA \& Robison LL 2001 Late mortality experience in five-year survivors of 
childhood and adolescent cancer: the childhood cancer survivor study. Journal of Clinical Oncology 19 3163-3172.

van Montfrans JM, Hoek A, van Hooff MH, de Koning CH, Tonch N \& Lambalk CB 2000 Predictive value of basal follicle-stimulating hormone concentrations in a general subfertility population. Fertility and Sterility 74 97-103. (doi:10.1016/S0015-0282(00)00560-4)

Najafi S, Djavid GE, Mehrdad N, Rajaii E, Alavi N, Olfatbakhsh A, Najafi M, Bahrami A \& Heidari K 2011 Taxane-based regimens as a risk factor for chemotherapyinduced amenorrhea. Menopause 18 208-212.

National Comprehensive Cancer Network - Breast Cancer Guidelines 2011. www.nccn.org, accessed June 2011.

Nelson SM, Messow MC, Wallace AM, Fleming R \& McConnachie A 2011 Nomogram for the decline in serum antiMüllerian hormone: a population study of 9,601 infertility patients. Fertility and Sterility 95 736-741. (doi:10.1016/j.fertnstert.2010.08.022)

Oktay K, Oktem O, Reh A \& Vahdat L 2006 Measuring the impact of chemotherapy on fertility in women with breast cancer. Journal of Clinical Oncology 24 4044-4046. (doi:10.1200/JCO.2006.06.9823)

Ortmann O, Pagani O, Jones A, Maass N, Noss D, Rugo H, van de Velde C, Aapro M \& Coleman R 2011 Which factors should be taken into account in perimenopausal women with early breast cancer who may become eligible for an aromatase inhibitor? Recommendations of an expert panel Cancer Treatment Reviews 37 97-104. (doi:10.1016/j.ctrv.2010.05.005)

Padmanabhan N, Howell A \& Rubens RD 1986 Mechanism of action of adjuvant chemotherapy in early breast cancer. Lancet 23 411-414. (doi:10.1016/S01406736(86)92131-8)

Partridge AH \& Ruddy KJ 2007 Fertility and adjuvant treatment in young women with breast cancer. Breast 16 (Suppl 2) 175-181. (doi:10.1016/j.breast.2007.07.029)

Partridge A, Gelber S, Gelber RD, Castiglione-Gertsch M, Goldhirsch A \& Winer E 2007 Age of menopause among women who remain premenopausal following treatment for early breast cancer: long-term results from International Breast Cancer Study Group Trials V and VI. European Journal of Cancer 43 1646-1653. (doi:10. 1016/j.ejca.2007.04.006)

Partridge AH, Ruddy KJ, Gelber S, Schapira L, Abusief M, Meyer M \& Ginsburg E 2010 Ovarian reserve in women who remain premenopausal after chemotherapy for early stage breast cancer. Fertility and Sterility 94 638-644. (doi:10.1016/j.fertnstert.2009.03.045)

Perez-Fidalgo JA, Rosello S, Garcıa-Garre E, Jordá E, Martín-Martorell P, Bermejo B, Chirivella I, Guzman C \& Lluch A 2010 Incidence of chemotherapy-induced amenorrhea in hormone-sensitive breast cancer patients: the impact of addition of taxanes to anthracycline-based regimens. Breast Cancer Research and Treatment 120 245-251. (doi:10.1007/s10549-009-0426-x)
Petrek JA, Naughton MJ, Case LD, Paskett ED, Naftalis EZ, Singletary SE \& Sukumvanich P 2006 Incidence, time course, and determinants of menstrual bleeding after breast cancer treatment: a prospective study. Journal of Clinical Oncology 24 1045-1051. (doi:10.1200/JCO. 2005.03.3969)

Roberts VJ, Barth S, el Roeiy A \& Yen SS 1993 Expression of inhibin/activin subunits and follistatin messenger ribonucleic acids and proteins in ovarian follicles and the corpus luteum during the human menstrual cycle.

Journal of Clinical Endocrinology and Metabolism 77 1402-1410. (doi:10.1210/jc.77.5.1402)

van Rooij IA, Tonkelaar I, Broekmans FJ, Looman CW, Scheffer GJ, de Jong FH, Themmen AP \& te Velde ER 2004 Anti-Mullerian hormone is a promising predictor for the occurrence of the menopausal transition. Menopause 11 601-606. (doi:10.1097/01.GME.0000123642.76105.6E)

van Rooij IA, Broekmans FJ, Scheffer GJ, Looman CW, Habbema JD, de Jong FH, Fauser BJ, Themmen AP \& te Velde ER 2005 Serum antiMullerian hormone levels best reflect the reproductive decline with age in normal women with proven fertility: a longitudinal study. Fertility and Sterility 83 979-987. (doi:10.1016/j.fertnstert.2004. 11.029)

Rose D \& Davis T 1980 Effects of adjuvant chemohormonal therapy on the ovarian and adrenal function of breast cancer patients. Cancer Research 40 4043-4047.

Rosendahl M, Andersen CY, La Cour Freiesleben N, Juul A, Løss1 K \& Andersen AN 2010 Dynamics and mechanisms of chemotherapy-induced ovarian follicular depletion in women of fertile age. Fertility and Sterility 94 156-166. (doi:10.1016/j.fertnstert.2009.02.043)

Rossi E, Morabito A, Di Rella F, Esposito G, Gravina A, Labonia V, Landi G, Nuzzo F, Pacilio C, De Maio E et al. 2009 Endocrine effects of adjuvant letrozole compared with tamoxifen in hormone-responsive postmenopausal patients with early breast cancer: the HOBOE trial. Journal of Clinical Oncology 27 3192-3197. (doi:10. 1200/JCO.2008.18.6213)

Schover LR 2008 Premature ovarian failure and its consequences: vasomotor symptoms, sexuality, and fertility. Journal of Clinical Oncology 26 753-758. (doi:10.1200/JCO.2007.14.1655)

Smith IE, Dowsett M, Yap YS, Walsh G, Lønning PE, Santen RJ \& Hayes D 2006 Adjuvant aromatase inhibitors for early breast cancer after chemotherapy-induced amenorrhea: caution and suggested guidelines. Journal of Clinical Oncology 24 2444-2447. (doi:10.1200/JCO. 2005.05.3694)

Sonmezer M \& Oktay K 2006 Fertility preservation in young women undergoing breast cancer therapy. Oncologist 11 422-434. (doi:10.1634/theoncologist.11-5-422)

Soules MR, Sherman S, Parrott E, Rebar R, Santoro N, Utian W \& Woods N 2001 Stages of Reproductive Aging Workshop (STRAW). Journal of Women's Health \& Gender-Based Medicine 10 843-848. (doi:10.1089/ 152460901753285732) 
Sowers MR, Eyvazzadeh AD, McConnell D, Yosef M, Jannausch ML, Zhang D, Harlow S \& Randolph JF Jr 2008 a Anti-Mullerian hormone and inhibin B in ovarian aging and the menopause transition. Journal of Clinical Endocrinology and Metabolism 93 3478-3483. (doi:10. 1210/jc.2008-0567)

Sowers MR, Zheng H, McConnell D, Nan B, Harlow SD \& Randolph JF Jr $2008 b$ Estradiol rates of change in relation to the final menstrual period in a population-based cohort of women. Journal of Clinical Endocrinology and Metabolism 93 3847-3852. (doi:10.1210/jc.2008-1056)

Stearns V, Schneider B, Henry NL, Hayes DF \& Flockhart DA 2006 Breast cancer treatment and ovarian failure: risk factors and emerging genetic determinants. Nature Reviews. Cancer 6 886-893. (doi:10.1038/nrc1992)

Su HI, Sammel MD, Velders L, Horn M, Stankiewicz C, Matro J, Gracia CR, Green J \& DeMichele A 2010 a Association of cyclophosphamide drug-metabolizing enzyme polymorphisms and chemotherapy-related ovarian failure in breast cancer survivors. Fertility and Sterility 94 645-654. (doi:10.1016/j.fertnstert.2009.03. 034)

Su HI, Sammel MD, Green J, Velders L, Stankiewicz C, Matro J, Freeman EW, Gracia CR \& DeMichele A $2010 b$ AntiMullerian hormone and inhibin $\mathrm{B}$ are hormone measures of ovarian function in late reproductive-aged breast cancer survivors. Cancer 116 592-599. (doi:10. 1002/cncr.24746)

Sukumvanich P, Case LD, Van Zee K, Singletary SE, Paskett ED, Petrek JA, Naftalis E \& Naughton MJ 2010 Incidence and time course of bleeding after long-term amenorrhea after breast cancer treatment: a prospective study. Cancer 116 3102-3111. (doi:10.1002/cncr.25106)

Sundaram B, Ohorodnik S, Settlage J \& Taylor P 2003 A bioanalytical method for the quantitation of estradiol, estrone, testosterone and dihydrotestosterone in human serum. AAPS PharmSciTech 5 (Supplement 1) 1058 abstract 8 .

Swain SM, Land SR, Ritter MW, Costantino JP, Cecchini RS, Mamounas EP, Wolmark N \& Ganz PA 2009 Amenorrhea in premenopausal women on the doxorubicin- and cyclophosphamide- followed-by-docetaxel arm of NSABP B-30 trial. Breast Cancer Research and Treatment 113 315-320. (doi:10.1007/s10549-0089937-0)

Swain SM, Jeong JH, Geyer CE Jr, Costantino JP, Pajon ER, Fehrenbacher L, Atkins JN, Polikoff J, Vogel VG, Erban JK et al. 2010 Longer therapy, iatrogenic amenorrhea, and survival in early breast cancer. New England Journal of Medicine 362 2053-2065. (doi:10.1056/NEJMoa0909638)
Tham YL, Sexton K, Weiss H, Elledge R, Friedman LC \& Kramer R 2007 The rates of chemotherapy induced amenorrhea in patients treated with adjuvant doxorubicin and cyclophosphamide followed by a taxane. American Journal of Clinical Oncology 30 126-132. (doi:10.1097/ 01.coc.0000251398.57630.4f)

Themmen AP 2005 Anti-Mullerian hormone: its role in follicular growth initiation and survival and as an ovarian reserve marker. Journal of the National Cancer Institute. Monographs 34 18-21. (doi:10.1093/jncimonographs/ lgi026)

Van Voorhis BJ, Santoro N, Harlow S, Crawford SL \& Randolph J 2008 The relationship of bleeding patterns to daily reproductive hormones in women approaching menopause. Obstetrics and Gynecology 112 101-108. (doi:10.1097/AOG.0b013e31817d452b)

Visser JA, de Jong FH, Laven JS \& Themmen AP 2006 AntiMullerian hormone: a new marker for ovarian function. Reproduction 131 1-9. (doi:10.1530/rep.1.00529)

Walshe J, Denduluri N \& Swain S 2006 Amenorrhea in pre-menopausal women after adjuvant chemotherapy for breast cancer. Journal of Clinical Oncology 24 5769-5779. (doi:10.1200/JCO.2006.07.2793)

Wang S, Paris F, Sultan CS, Song RX, Demers LM, Sundaram B, Settlage J, Ohorodnik S \& Santen RJ 2005 Recombinant cell ultrasensitive bioassay for measurement of estrogens in postmenopausal women. Journal of Clinical Endocrinology and Metabolism 90 1407-1413. (doi:10.1210/jc.2004-0766)

Yu B, Douglas N, Ferin MJ, Nakhuda GS, Crew K, Lobo RA \& Hershman DL 2010 Changes in markers of ovarian reserve and endocrine function in young women with breast cancer undergoing adjuvant chemotherapy. Cancer 116 2099-2105.

Zhou WB, Yin H, Liu XA, Zha XM, Chen L, Dai JC, Tao AD, Chen L, Ma JJ, Linng LJ et al. 2010 Incidence of chemotherapy-induced amenorrhea associated with epirubicin, docetaxel and navelbine in younger breast cancer patients. BMC Cancer 10 281. (doi:10.1186/1471-240710-281)

de Ziegler D, Mattenberger C, Luyet C, Romoscanu I, Irion NF \& Bianchi-Demicheli F 2005 Clinical use of aromatase inhibitors (AI) in premenopausal women. Journal of Steroid Biochemistry and Molecular Biology 95 121-127. (doi:10.1016/j.jsbmb.2005.04.023)
Received in final form 3 January 2012
Accepted 9 January 2012
Made available online as an Accepted Preprint 12 January 2012 